\title{
SENAM KAKI LEBIH EFEKTIF MENINGKATKAN SIRKULASI DARAH KE KAKI DIBANDING PENURUNAN KADAR GLUKOSA PADA PENDERITA DIABETES MELLITUS DI WILAYAH KERJA PUSKESMAS REJOSO
}

\author{
More Effectivenes Foot Exercise In Improving Blood Circulation For Legs With \\ Reducing Of Glucose Levels For Diabetes Mellitus Patients \\ In Rejoso Health Center
}

\author{
Erni Tri Indarti ${ }^{1}$, Hendri Palupi ${ }^{2}$ \\ ${ }^{1,2}$ Dosen STIKes Satria Bhakti Nganjuk \\ Email triindarti77@gmail.com
}

\begin{abstract}
ABSTRAK
Diabetes Melitus merupakan sekelompok kelainan heterogen yang ditandai oleh kenaikan kadar glukosa dalam darah atau hiperglikemia. Senam kaki merupakan latihan yang dilakukan bagi penderita DM atau bukan penderita untuk mencegah terjadinya luka dan membantu melancarkan peredaran darah bagian kaki (Soebagio, 2011). Tujuan Penelitian ini untuk mengetahui Senam Kaki Lebih Efektif Meningkatkan Sirkulasi Darah Ke Kaki Dibanding Penurunan Kadar Glukosa Pada Penderita Diabetes Mellitus Di Wilayah Kerja Puskesmas Rejoso. Penelitian ini merupakan jenis penelitian Pra - Experiment dengan One Pre-Post Test Design. Penelitian ini dilakukan tanggal 20 Juli - 20 Agustus 2018 di Wilayah kerja Puskesmas Rejoso. Sampel dalam penelitian ini penderita Diabetes Mellitus yang memenuhi kriteria inklusi sebanyak 30 orang. Teknik sampling dalam penelitian ini menggunakan purposive sampling. Instrumen penelitian yang digunakan adalah Video Senam Kaki, Stetoskop Merk Onemed, Spygnomanometer Merk Onemed, Glukotest Merk EasyTooth. Analisis bivariat untuk mengetahui perbedaan Nilai ABPI dan Gula darah responden sebelum dan sesudah dilakukan intevensi dengan uji Wilcoxon. Berdasarkan hasil uji wilcoxon didapatkan p-value nilai ABPI $0,000 \leq \alpha(0,05)$ dan p-value gula darah $0,006 \leq \alpha(0,05)$, sehingga Ha diterima dan ada pengaruh senam kaki terhadap perubahan nilai ABPI dan gula darah pada penderita diabetes mellitus, hal ini berarti ada pengaruh senam kaki terhadap Sirkulasi Darah Ke Kaki pada penderita diabetes mellitus dengan rata-rata penurunan nilai $\mathrm{ABPI}$ 0,124 dan rata-rata penurunan gula darah sebesar 11,37.
\end{abstract}

Kata Kunci : Senam Kaki, Diabetes Mellitus, Gula Darah, Sirkulasi Darah ke kaki

\begin{abstract}
Diabetes mellitus is a group of heterogeneous disorders characterized by increased levels of glucose in the blood or hyperglycemia. Foot exercises are exercises that are performed for people with DM or non-sufferers to prevent injury and help to improve blood circulation in the legs (Soebagio, 2011). The aims of this study to out that foot exercises are more effective in increasing blood circulation to the feet than the decrease in glucose levels in people with diabetes mellitus in the work area of the Rejoso health center. This research is a type of Pre-Experiment research with One Pre-Post Test Design. This research was conducted on 20 July - 20 August 2018 in the working area of the Rejoso Health Center. The sample in this study were Diabetes Mellitus patients who met the inclusion criteria of 30 people. The sampling technique in this study uses purposive sampling. The research instrument used was Foot Gymnastics Video, Stethoscope Brand Onemed, Spygnomanometer Brand Onemed, Glukotest Brand EasyTooth. Bivariate analysis to determine differences in ABPI values and respondent blood sugar before and after intervention with the Wilcoxon test. Based on Wilcoxon test results obtained p-value ABPI value $0,000 \leq \alpha(0,05)$ and p-value of blood sugar 0,006 $\leq \alpha(0,05)$, so that Ha is accepted and there is influence of foot gymnastics on changes in ABPI values and blood sugar in patients diabetes mellitus, this means that there is an influence of foot exercises on Blood to Leg Circulation in patients with diabetes mellitus with an average decrease in ABPI value of 0.124 and an average decrease in blood sugar of 11.37.
\end{abstract}

Keywords : Diabetic Foot Exercise, Diabetes Mellitus, blood sugar, Leg Circulation 


\section{PENDAHULUAN}

Diabetes Melitus merupakan sekelompok kelainan heterogen yang ditandai oleh kenaikan kadar glukosa dalam darah atau hiperglikemia. Glukosa secara normal bersirkulasi dalam jumlah tertentu dalam darah.Glukosa dibentuk di hati dari makanan yang dikonsumsi. Insulin yaitu suatu hormon yang diproduksi oleh pankreas, mengendalikan kadar glukosa dalam darah dengan mengatur produksi dan penyimpanannya (Brunner \& Sudarth, 2001). Salah satu komplikasi penyakit diabetes melitus yang sering dijumpai adalah kaki diabetik (diabetic foot), yang dapat ber manifestasikan sebagai ulkus, infeksi dan gangren dan artropati Charcot (Reptuz, 2009; dikutip Andarwanti, 2009). Ada dua tindakan dalam prinsip dasar pengelolaan diabetic foot yaitu tindakan pencegahan dan tindakan rehabilitasi. Tindakan rehabilitasi meliputi program terpadu yaitu evaluasi tukak, pengendalian kondisi metabolik, debridemen luka, biakan kuman, antibiotika tepat guna, tindakan bedah rehabilitatif dan rehabilitasi medik. Tindakan pencegahan meliputi edukasi perawatan kaki, sepatu diabetes dan senam kaki (Yudhi, 2009).

Senam kaki merupakan latihan yang dilakukan bagi penderita DM atau bukan penderita untuk mencegah terjadinya luka dan membantu melancarkan peredaran darah bagian kaki (Soebagio, 2011), (Anggriyana \& Atikah, 2010). Perawat sebagai salah satu tim kesehatan, selain berperan dalam memberikan edukasi kesehatan juga dapat berperan dalam membimbing penderita DM untuk melakukan senam kaki sampai dengan penderita dapat melakukan senam kaki secara mandiri

Gerakan-gerakan senam kaki ini dapat memperlancar peredaran darah di kaki, memperbaiki sirkulasi darah, memperkuat otot kaki dan mempermudah gerakansendi kaki. Dengan demikian diharapkan kaki penderita diabetes dapat terawat baik dan dapat meningkatkan kualitas hidup penderita diabetes (Anneahira, 2011).

Menurut (Wibisono, 2009) yang menjadi Ketua Persatuan Diabetes Indonesia, senam kaki ini berpengaruh untuk memperbaiki sirkulasi darah.Dari pengamatan (Dian, 2008) di Rumah Sakit. Dr. Oen Solo Baru pada tanggal 7 Mei 2007 banyak penderita Diabetes Melitus yang mengikuti senam kaki, karena disamping menyehatkan tubuh juga sangat memungkinkan untuk dapat mengikutinya. Dian juga pernah melakukan penelitian tentang senam ini pada tahun 2009.Tetapi pada penelitian tersebut memfokuskan pada lansia saja. Pada tahun yang sama (Cinta, 2009) juga melakukan penelitian tentang pengaruh senam kaki dalam mencegah kaki diabetik, kemudian (Julian, 2010) melakukan penelitian tentang pengaruh senam kaki terhadap peningkatan sirkulasi darah kaki pada pasien DM di RSUP Haji Adam Malik Medan yaitu rata-rata sirkulasi darah kaki sebelum dilakukan senam kaki $0,94 \mathrm{mmHg}$ dan sesudah dilakukan senam kaki terjadi peningkatan sirkulasi darah kaki menjadi 1,90 mmHg. Berdasarkan data di Wilayah Puskesmas Rejoso kejadian diabetes mellitus tahun 2018 sebanyak 30 orang. Berdasarkan wawancara dengan penderita diabetes mellitus, mereka belum pernah melakukan senam kaki, mereka sudah mendapatkan informasi tentang senam kaki tetapi belum melakukan.

Neuropati perifer atau kerusakan saraf merupakan komplikasi serius dari diabetes. Data terbaru menunjukkan bahwa satu dari lima orang dengan diabetes $(20 \%)$ memiliki neuropati perifer. Resiko neuropati perifer adalah sekitar 2 kali lipat lebih tinggi dibandingkan orang tanpa diabetes.Kombinasi neuropati perifer dengan masalah yang terkait dengan suplai darah ke kaki dapat menyebabkan ulkus kaki dan penyembuhan luka lambat.Infeksi ini dapat mengakibatkan luka amputasi, 40-70\% dari seluruh amputasi ekstremitas bawah disebabkan oleh Diabetes Melitus.

Keadaan kaki diabetik lanjut yang tidak ditangani secara tepat dapat berkembang menjadi suatu tindakan pemotongan amputasi kaki. Adanya luka dan masalah lain pada kaki merupakan penyebab utama, morbiditas, disabilitas, dan mortalitas pada seseorang yang menderita diabetes melitus (Prabowo, 2007). Komplikasi yang paling sering dialami pengidap diabetes adalah komplikasi pada kaki (15 persen) yang kini disebut kaki diabetes.(Akhtyo, 2009).

Dari sudut ilmu kesehatan, tidak diragukan lagi bahwa olah raga apabila dilakukan sebagaimana mestinya menguntungkan bagi kesehatan dan kekuatan pada umumnya.Selain itu telah lama pula olah raga, digunakan sebagai bagian pengobatan diabetes melitus namun tidak semua olah raga 
dianjurkan bagi pengidap diabetes melitus (bagi orang normal juga demikian) karena dapat menimbulkan hal-hal yang tidak diharapkan.Olahraga, yang dilakukan adalah olahraga yang terukur, teratur, terkendali dan berkesinambungan. Frekuensi yang dianjurkan adalah 3-5 kali perminggu.Intensitas yang dianjurkan sebesar 40-70\% (ringan sampai sedang).Salah satu jenis olah raga, yang dianjurkan terutama, pada penderita, usia, lanjut adalah senam kaki (Akhtyo, 2009).

\section{Metode Penelitian}

Penelitian ini merupakan jenis penelitian Pra - Experiment dengan One Pre-Post Test Design. Penelitian ini dilakukan tanggal 20 Juli - 20 Agustus 2018 di Wilayah kerja Puskesmas Rejoso. Sampel dalam penelitian ini penderita Diabetes Mellitus yang memenuhi kriteria inklusi sebanyak 30 orang. Teknik sampling dalam penelitian ini menggunakan purposive sampling dengan kriteria inklusi penderita Diabetes Mellitus yang mengikuti kegiatan Prolanis secara rutin, melakukan senam kaki 3 kali 1 minggu dengan rentang 20-30 menit selama 4 minggu, bersedia menjadi responden. Instrumen penelitian yang digunakan adalah Video Senam Kaki, Stetoskop Merk Onemed, Spygnomanometer Merk Onemed, Glukotest Merk EasyTooth. Data diambil 2 tahap Pertama mengukur Gula Darah dan Nilai ABPI sebelum intervensi. Tahap kedua setelah dilakukan intervensi selama 4 minggu mengukur Gula Darah dan Nilai ABPI kembali.

Analisis univariat meliputi mean, standart deviasi, nilai terendah, nilai tertinggi dan confidens interval dari data umum, Nilai ABPI dan Gula Darah. Analisis bivariat untuk mengetahui perbedaan Nilai ABPI dan Gula darah responden sebelum dan sesudah dilakukan intevensi dengan uji Wilcoxon.

\section{HASIL DAN PEMBAHASAN}

1. Karakteristik Responden

Tabel 1. Distribusi responden berdasarkan jenis kelamin, Usia, Berat Badan dan lama menderita Diabetes Mellitus di wilayah kerja Puskesmas Rejoso 20 Juli20 Agustus $2018(n=30)$

\begin{tabular}{|c|c|c|}
\hline Variabel & Frekuensi & $\begin{array}{c}\text { Prosentase } \\
(\%)\end{array}$ \\
\hline \multicolumn{3}{|l|}{ Jenis Kelamin } \\
\hline Laki-laki & 5 & 16,7 \\
\hline Perempuan & 25 & 83,3 \\
\hline \multicolumn{3}{|l|}{ Umur } \\
\hline 41-50 Tahun & 3 & 10 \\
\hline 51-60 Tahun & 10 & 33,3 \\
\hline 61-70 Tahun & 12 & 40 \\
\hline 71-80 Tahun & 5 & 16,7 \\
\hline 81-90 Tahun & 0 & 0 \\
\hline \multicolumn{3}{|l|}{ Berat Badan } \\
\hline $30-40 \mathrm{Kg}$ & 3 & 10 \\
\hline $41-50 \mathrm{Kg}$ & 5 & 16,7 \\
\hline $51-60 \mathrm{Kg}$ & 12 & 40 \\
\hline $61-70 \mathrm{Kg}$ & 7 & 23,3 \\
\hline $71-80 \mathrm{Kg}$ & 3 & 10 \\
\hline \multicolumn{3}{|l|}{ Lama } \\
\hline \multicolumn{3}{|l|}{ Menderita } \\
\hline 1-10 Tahun & 8 & 26,7 \\
\hline 11-20 Tahun & 12 & 40 \\
\hline 21-30 Tahun & 10 & 33,3 \\
\hline Hasil & penelitian & menunjul \\
\hline
\end{tabular}

bahwa hampir seluruhnya yaitu 25 responden $(83,3 \%)$ berjenis kelamin perempuan, hampir setengahnya yaitu 12 responden (40\%) berusia 61-70 Tahun, hampir setengahnya yaitu 12 responden (40\%) memiliki berat badan $51-60 \mathrm{Kg}$ dan hampir setengahnya yaitu 12 responden $(40 \%)$ lama menderita Diabetes Mellitus 11-20 Tahun.

Hasil penelitian ini sesuai dengan teori yang mengemukakan bahwa DM tipe 2 ada akibat dari meningkatnya umur dan penyebab DM tipe 2 salah satunya umur lebih dari 40 tahun (Lewis et al, 2011; Black \& Hawk, 2009). Penelitian ini juga sesuai dengan penelitian Natalia, Hasneli, \& Novayelinda, 2012; yang menjelaskan bahwa umur pasien DM tipe 2 adalah orang dewasa lebih banyak ditemukan karena semakin besar umur seseorang maka sirkulasi darah kearah daerah perifer menurun. Menurut Hastuti (2008) dalam penelitiannya didapatkan bahwa umur pasien DM tipe 2 lebih dari 40 tahun, dan tidak ada hubungannya antara umur dengan kejadian diabetik. 
Penelitian ini sejalan dengan penelitian Roza, Afriant, \& Edward, 2015 didapatkan bahwa perempuan paling banyak menderita DM . Penelitian Purwanti (2013) dinyatakan bahwa tidak ada hubungan yang signifikan terjadinya luka diabetes antara lakilaki dan perempuan dan berbeda hasil penelitian yang lain tentang kejadian ulkus diabetikum bahwa perempuan lebih banyak ditemukan ulkus diabetik (Roza et al., 2015; Nyamu et al., 2003). Menurut Bennett, 2008 Kejadian DM Tipe 2 pada wanita lebih tinggi daripada laki-laki.Wanita lebih berisiko mengidap diabetes karena secara fisik wanita memiliki peluang peningkatan indeks masa tubuh yang lebih besar.

Menurut Burraerah, 2010 Terdapat korelasi bermakna antara obesitas dengan kadar glukosa darah, pada derajat kegemukan dengan IMT > 23 dapat menyebabkan peningkatan kadar glukosa darah menjadi $200 \mathrm{mg} \%$.

\section{Sirkulasi Darah Ke Kaki}

Tabel 2 Nilai ABPI sebelum dan sesudah melakukan Senam Kaki Penderita Diabetes Mellitus di wilayah kerja Puskesmas Rejoso 20 Juli-20 Agustus $2018(n=30)$

\begin{tabular}{lccccc}
\hline Nilai ABPI & N & Mean & SD & $\mathbf{9 5 \%}$ CI & p-value \\
\hline $\begin{array}{l}\text { Sebelum } \\
\text { Senam }\end{array}$ & 30 & 0,833 & 0,135 & $0,782 \pm 0,884$ & 0,253 \\
Kaki & & & & &
\end{tabular}

Sesudah

$\begin{array}{llllll}\text { Senam } & 30 & 0,957 & 0,159 & 0,898 \pm 1,017 & 0,011 \\ \text { Kaki } & & & & \end{array}$

Tabel 3 Perubahan Nilai ABPI sebelum dan sesudah melakukan Senam Kaki Penderita Diabetes Mellitus di wilayah kerja Puskesmas Rejoso 20 Juli-20 Agustus $2018(n=30)$

\begin{tabular}{|c|c|c|c|c|c|}
\hline $\begin{array}{c}\text { Peruba } \\
\text { han } \\
\text { Nilai } \\
\text { ABPI }\end{array}$ & $\mathbf{N}$ & Mean & SD & $95 \% \mathrm{CI}$ & $\begin{array}{c}\text { p- } \\
\text { value }\end{array}$ \\
\hline $\begin{array}{l}\text { Pre- } \\
\text { Post }\end{array}$ & 30 & 0,124 & 0,157 & $\begin{array}{c}0,065 \pm \\
0,183\end{array}$ & 0,000 \\
\hline
\end{tabular}

didapatkan p-value $0,000 \leq \alpha(0,05)$, sehingga Ha diterima dan ada pengaruh senam kaki terhadap perubahan nilai ABPI pada penderita diabetes mellitus, hal ini berarti ada pengaruh senam kaki terhadap Sirkulasi Darah Ke Kaki pada penderita diabetes mellitus dengan ratarata penurunan nilai $\mathrm{ABPI} 0,124$.

Hasil penelitian ini sejalan dengan penelitian Wahyuni A dan Arisfa N, 2016 menunjukkan ada perbedaan nialai ABPI sebelum dan sesudah dilakukan senam kaki pada penderita diabetes mellitus tipe 2 . Menurut penelitian Sabar dan Priyanto, 2017 ada perbedaan secara bermakna rata-rata sensitivitas kaki sebelum dilakukan senam kaki dengan sensitivitas kaki setelah dilakukan senam kaki pada kelompok intervensi (t:14,87 dan p-value 0,000).

Indikator penurunan perfusi ke daerah tungkai dapat diukur melalui ABPI. ABPI adalah rasio dari tekanan darah sistolik yang diukur di area kaki dan yang diukur di arteri brachial dan digunakan untuk mengetahui adanya PAD salah satunya disebabkan oleh penyaki DM (Aboyans et al., 2012). ABPI digunakan untuk mengetahui jumlah aliran darah ke kaki, ABPI diukur menggunakan spignomanometer dan dopler, pengukurannya serupa dengan mengukur tekanan darah namun pada ABPI tekanan darah yang diukur yaitu pada tangan dan kaki (Nursing Skin and Wound Care, 2013). Nilai yang diambil adalah tekanan darah sistolik yang tertinggi pada kedua kaki dibagi tekanan sistolik tertinggi di kedua tangan. Interpretasi ABPI menunjukan keadaan sirkulasi darah pada tungkai bawah, menurut Aboyans et al (2012)terdiri dari empat kategori yaitu normal $(\geq 0.90) ;$ obstruksi ringan $(0.71-0.90)$; obstruksi sedang (0.41-0.70); dan obstruksi berat $(\leq 0.40)$.

Senam kaki merupakan cara yang tepat untuk melancarkan sirkulasi terutama ke daerah kaki.Senam kaki merupakan salah satu senam aerobic yang variasi gerakangerakannya pada daerah kaki memenuhi kriteria continous, rhythmical, interval, progresif dan endurance sehingga setiap tahapan gerakan harus dilakukan. Senam yang dianjurkan pada pasien DM yang bersifat aerobik artinya membutuhkan oksigen dan dapat membantu sirkulasi darah, memperkuat otot-otot kecil kaki, mencegah terjadinya kelainan bentuk kaki yang dapat meningkatkan potensi luka diabetik di kaki, meningkatkan produksi insulin yang dipakai dalam transport glukosa ke sel sehingga membantu menurunkan glukosa dalam darah(Dewi, Sumarni, \& Sundari, 2012). Gerakan-gerakan kaki yang dilakukan selama 
senam kaki diabetik sama halnya dengan pijatbel kaki yaitu memberikan tekanan dan gerakan pada kaki mempengaruhi hormon yaitu meningkatkan sekresi endorphin yang berfungsi sebagai menurunkan sakit, vasodilatasi pembuluh darah sehingga terjadi penurunan tekanan darah terutama sistolik brachialis yang berhubungan langsung dengan nilai ABI (Laksmi, Agung, Mertha, \& Widianah, 2006). Senam kaki menjadikan tubuh menjadi rileks dan melancarkan peredaran darah. Peredaran darah yang lancar akibat digerakkan, menstimulasi darah mengantar oksigen dan gizi lebih banyak ke sel-sel tubuh, selain itu membantu membawa racun lebih banyak untuk dikeluarkan (Natalia et al., 2012). Dalam gerakan senam kaki juga terdapat peregangan kaki (stretching). Stretching kaki dianggap efektif melancarkan sirkulasi darah ke daerah kaki, meningkatkan kerja insulin dan melebarkan pembuluh darah yang diakui berperan serta meningkatkan tekanan sistolik pada kaki (Witari, Triyani, \& Dewi, 2015).

Pendapat Stanhope \& Lancaster, 2004 yang menyatakan bahwa kadar gula darah tinggi akan menjadikan viskositas atau kekentalan darah tinggi, sehingga akan menghambat sirkulasi darah dan persyarafan terutama daerah atau ujung kaki sebagai tumpuan tubuh utama. Viskositas yang tinggi ini juga akan meningkatkan kemampuan bakteri untuk merusak sel-sel tubuh, sehingga kalau terjadi luka cenderung sulit atau lama proses penyembuhannya. Salah satu upaya yang dapat membantu meningkatkan sirkulasi darah yaitu melakukan aktivitas atau latihan terutama menggerakkan kaki.

\section{Gula Darah}

Tabel 4 Nilai Gula Darah sebelum dan sesudah melakukan Senam Kaki Penderita Diabetes Mellitus di wilayah kerja Puskesmas Rejoso 20 Juli-20 Agustus $2018(n=30)$

\begin{tabular}{lccccc}
\hline $\begin{array}{l}\text { Nilai Gula } \\
\text { Darah }\end{array}$ & N & Mean & SD & 95\% CI & $\begin{array}{c}\text { p- } \\
\text { value }\end{array}$ \\
\hline $\begin{array}{l}\text { Sebelum } \\
\text { Senam }\end{array}$ & 30 & 239,766 & 77,365 & $\begin{array}{l}210,878 \pm \\
268,655\end{array}$ & 0,000 \\
Kaki & & & & & \\
& & & & & \\
Sesudah & 30 & 228,4 & 68,851 & $202,69 \pm$ & 0,000 \\
Senam & & & & 254,109 & \\
Kaki & & & & & \\
\hline
\end{tabular}

Perubahan Nilai Gula Darah sebelum dan sesudah melakukan Senam Kaki Penderita Diabetes Mellitus di wilayah kerja Puskesmas Rejoso 20 Juli-20 Agustus $2018(n=30)$

\begin{tabular}{cccccc}
\hline $\begin{array}{c}\text { Perubahan } \\
\text { Nilai Gula } \\
\text { Darah }\end{array}$ & N & Mean & SD & $\begin{array}{c}\text { 95\% } \\
\text { CI }\end{array}$ & $\begin{array}{c}\text { p- } \\
\text { value }\end{array}$ \\
\hline Pre-Post & 30 & 11,37 & 23,15 & $2,72 \pm$ & 0,006 \\
& & & 20,01 & \\
\hline
\end{tabular}

Berdasarkan hasil uji wilcoxon didapatkan p-value $0,006 \leq \alpha(0,05)$, sehingga Ha diterima dan ada pengaruh senam kaki terhadap perubahan Nilai gula darah pada penderita diabetes mellitus dengan rata-rata penurunan gula darah sebesar 11,37.

Hasil penelitian ini sejalan dengan penelitian Indriyani dkk, 2010 ada pengaruh latihan fisik senam aerobik terhadap penurunan kadar gula darah pada penderita diabetes mellitus (p-value 0,0001) dengan penurunan rata-rata $30,14 \mathrm{mg} \%$. Latihan fisik pada penderita Diabetes Mellitus memiliki peranan yang sangat penting dalam mengendalikan kadar gula dalam darah, dimana saat melakukan latihan fisik terjadi peningkatan pemakaian glukosa oleh otot yang aktif sehingga secara langsung dapat menyebabkan penurunan glukosa darah. Adanya pengaruh latihan fisik: senam aerobik terhadap penurunan kadar gula darah ini disebabkan karena senam aerobik merupakan suatu proses yang sistematis dengan menggunakan rangsangan gerak yang bertujuan untuk meningkatkan atau mempertahankan kualitas fungsional tubuh yang meliputi kualitas daya tahan parujantung, kekuatan dan daya tahan otot, kelenturan dan komposisi tubuh (Irianto, 2000).

Menurut WHO, 2008, diabetes melitus merupakan keadaan hiperglikemia kronis yang disebabkan oleh faktor lingkungan dan keturunan secara bersama-sama, dan mempunyai karakteristik hiperglikemia kronis tidak dapat disembuhkan tetapi dapat dikontrol. Faktor utama yang harus dikendalikan adalah nilai kadar gula darah, diupayakan dalam rentang normal atau mendekati rentang normal. Tingginya angka atau kadar gula darah menunjukkan tingkat kesakitan yang terjadi. Tanda-tanda awal yang biasanya dirasakan lansia seperti banyak makan, banyak kencing, banyak minum seandainya dilakukan pemeriksaan gula darah 
lebih lanjut akan menunjukkan adanya peningkatan.

\section{KESIMPULAN DAN SARAN}

1. Kesimpulan

Berdasarkan hasil uji wilcoxon didapatkan $\mathrm{p}$-value $0,000 \leq \alpha(0,05)$, sehingga Ha diterima dan ada pengaruh senam kaki terhadap perubahan nilai ABPI pada penderita diabetes mellitus, hal ini berarti ada pengaruh senam kaki terhadap Sirkulasi Darah Ke Kaki pada penderita diabetes mellitus dengan ratarata penurunan nilai ABPI 0,124.

Berdasarkan hasil uji wilcoxon didapatkan p-value $0,006 \leq \alpha(0,05)$, sehingga Ha diterima dan ada pengaruh senam kaki terhadap perubahan Nilai gula darah pada penderita diabetes mellitus dengan rata-rata penurunan gula darah sebesar 11,37.

2. Saran

a. Bagi Puskesmas, perlu adanya pelatihan senam kaki oleh puskesmas pada lansia di wilayah kerjanya, melalui kegiatan posbindu. Sedangkan kader kesehatan posbindu ikut memotivasi dan memonitor kegiatan selanjutnya yang dilakukan secara teratur dan kontinu.

b. Penelitian berikutnya, perlu diteliti lebih lanjut dengan menggunakan variabel perancu lain yang dapat mempengaruhi sensitivitas kaki dan kadar gula darah seperti faktor obat-obatan, penyakit yang diderita, makanan dan minuman serta kekuatan otot. Perlu dikembangkan untuk penelitian yang akan datang mengenai lamanya intervensi, waktu latihan senam kaki, pagi atau sore.

\section{DAFTAR PUSTAKA}

Aboyans, V., Criqui, M. H., Abraham, P., Allison, M. A., Creager, M. A., Diehm, C., ... Stoffers, H. E. J. (2012). Measurement and Interpretation of the Ankle-Brachial Index A Scientific Statement From the American Heart Association Rationale for Standardization of the ABI. AHA Journal.

Bennett,P. Epidemiology Type 2 Diabetes Millitus. In Le Roithet.al, Diabetes Mellitus Fundamental and Clinical Text. Philadelphia : Lippi

Bennett,P.EpidemiologyofType2DiabetesMill itus.InLeRoithet.al,DiabetesMillitusaFun
damentalandClinical

Text.Philadelphia:LippincottWilliam\&W ilkin s.2008;43(1): 544-7.

Brunner \& Suddart. (2001). Keperawatan Medikal Bedah Brunner \& Sudarth. Vol2. EGC : Jakarta.

Buraerah, Hakim. Analisis Faktor Risiko Diabetes Melitus tipe 2 di Puskesmas Tanrutedong, Sidenreg Rappan,. Jurnal Ilmiah Nasional;2010 [cited 2010 feb 17]. Available from :http://lib.atmajaya.ac.id/default.aspx?tab $\mathrm{ID}=61 \& \mathrm{src}=\mathrm{a} \& \mathrm{id}=186192$

Dewi, P., Sumarni, T., \& Sundari, R. I. (2012). Pengaruh Senam Diabetes Mellitus dengan Nilai Abi (Ankle Brachial Index ) pada Pasien Diabetes Mellitus di Puskesmas Padamara Purbalingga. Jurnal STikes Harapan Bunda, 5, 1-6. Retrieved from jurnal.shb.ac.id

Hidayat, Aziz Alimul. (2007). Riset Keperawatan dan Teknik Penulisan Ilmiah. Salemba, Medika : Jakarta.

Ibrahim, dkk. 2012. Pengaruh Senam Kaki Terhadap Peningkatan Sirkulasi Darah Kaki Pada Pasien Penderita Diabetes Melitus Tipe 2 Di RSUP Fatmawati Jakarta. Media Ners.

Indriyani, Supriyatno, Santoso. 2007. Pengaruh Latihan Fisik; Senam Aerobik Terhadap Penurunan Kadar Gula Darah Pada Penderita Dm Tipe 2 Di Wilayah Puskesmas Bukateja Purbalingga. Media Ners. Volume 1, Nomor 2, Tahun 2007, hlm 49 - 99 89. Diakses 1 April 2016

Indriyani dkk. 2010. Pengaruh latihan fisik senam aerobik terhadap penurunan kadar gula darah pada diabetes Mellitus di wilayah Puskesmas Bukateja Purbalingga. Nurse Media Journal Of Nursing I(2). Ejournal.Undip.ac.id

Irianto,D.P. 2000. Panduan latihan kebugaran fisik ( yang efektif dan aman). Yogyakarta: Lukman Offset.

Kariadi. (2009). Panduan Lengkap untuk 
Diabetisi, Keluarganya, dan Profesional Medis. Qanita PT Mizan Pustaka, Anggota IKAPI. Bandung.

Laksmi, Agung, I. A., Mertha, I. M., \& Widianah, L. (2006). Pengaruh Foot Massage Terhadap Ankle Brachial Index (ABI) Pada Pasien DM Tipe 2 Di Puskesmas II Denpasar Barat. Journal Of Udayana.

Natalia, N., Hasneli, Y., \& Novayelinda, R. (2012). Efektifitas senam kaki diabetik dengan tempurung kelapa terhadap tingkat sensitivitas kaki pada pasien diabetes melitus 2. Jom Unri, 1-9.

Notoadmodjo. (2010). Metodologi Penelitian Kesehatan. PT.Rineka Cipta. Jakarta.

Nursalam. (2003). Konsep dan Penerapan Metodologi Penelitian Ilmu Keperawatan. Edisi 2. Salemba. Medika : Jakarta.

Nursing Skin and Wound Care. (2013). Procedure: Ankle Brachial Index (ABI) in Adults Using a Handheld Doppler. British Columbia Provincial.

Sabar J, Priyanto S. 2017. Pengaruh Senam Kaki Terhadap Sensitivitas Kaki dan Kadar Gula Darah Pada Agregat Lansia Diabetes Melitus di Magelang. Jurnal. Unimus.ac.id

Soegondo Sidartawan ddk. (2009). Penatalaksanaan Diabetes Melitus Terpadu. Edisi 2. Cetakan 7. Balai Penerbit FKUI : Jakarta.

Soebagio, Imam. 2011. Senam Kaki Sembuhkan Diabetes Mellitus. Diakses dari

http://pakdebagio.blogspot.com/2011/04/ senam-kaki-sembuhkan-diabetesmelitus.html. Diperoleh tanggal 1 April 2016.

Stanhope, M., \& Lancaster, J. (2004). Community \& public health nursing. Sixth edition. St Louis Missouri: Mosby.
Tandra, Hans. (2008). Segala Sesuatu yang Harus Anda Ketahui tentang Diabetes. Jakarta : PT Gramedia Pustaka Umum

Wahyuni A dan Arisfa N. 2016. Senam kaki diabetik efektif meningkatkan ABPI pasien Disbetes mellitus ii. Research Of Applied Science and Education V9.i2 (155-164)

Widianti Tri Anggriyana. (2010). Senam Kesehatan. Cetakan I. Nuha Medika: Yogyakarta

WHO (2008), Technical brief for Policy Maker, Geneva, Switzerland

Yudhi. 2009. Senam Kaki. Diakses dari http://www.kesad.mil.id/content/senamkaki . Diperoleh tanggal 1 April 2016. 